\title{
Technobius
}

\section{Toe drain size and slope stability of homogeneous embankment dam under rapid drawdown}

\author{
Dimoth Mkilima ${ }^{1,2,3, *}$ \\ ${ }^{1}$ Pan-African University Institute for Water and Energy Sciences (including Climate Change) c/o Tlemcen University, \\ B.P. 119 | Pôle Chetouane, Tlemcen 13000, Algeria. \\ ${ }^{2}$ Department of Civil Engineering, L.N. Gumilyov Eurasian National University,010008 Nur-Sultan, Kazakhstan. \\ ${ }^{3}$ Ardhi University, Plot Number 3 Block L, Observation Hill, P.O. Box 35176, Dar es Salaam, Tanzania. \\ *Correspondence: tmkilima@gmail.com
}

\begin{abstract}
The slope stability of an embankment dam has always been a serious issue of concern for any design team. Unfortunately, the information on the potential influence of a toe drain size on the slope stability of an embankment dam under rapid drawdown conditions is still scarce. This study investigated the potential effect of a toe drain size on the slope stability of a homogeneous embankment dam under rapid drawdown conditions. Three different sizes $(5 \mathrm{~m}, 10 \mathrm{~m}$, and $15 \mathrm{~m}$ ) of the toe drain were investigated under instantaneous (worst scenario) and 5 days (more realistic) drawdown rates with the help of numerical modeling in GeoStudio. From the results, it was observed that the pore-water pressures at the upstream face of the embankment decreased with the increase in the toe drain size, while the pore-water pressures at the downstream toe were increasing with the increase in the toe drain size. The factor of safety values were also observed to be affected by the changes in the toe drain size. The $5 \mathrm{~m}$ drain size had a minimum size of 0.961 , the $10 \mathrm{~m}$ drain size had a minimum factor of safety of 0.970 , while the $15 \mathrm{~m}$ drain size had a minimum factor of safety of 0.978 .
\end{abstract}

Keywords: slope stability, embankment dam, seepage, toe drain, rapid drawdown, factor of safety.

\section{Introduction}

Slope stability is among the serious issues of concern when designing embankment dams. This is due to the fact that the inappropriate design of embankment dams increases the risk of failure leading to catastrophic consequences [1]. A toe drain is among the features of embankment dams that have to be properly investigated during the design and operation phases under different loading conditions [2].

Among many other factors, seepage remains to be a very important factor that has to be carefully investigated and controlled when designing embankment dams [3]. The significance of controlling seepage is brought by the fact that excessive seepage through the embankment can pose a significant threat to the stability of the dam and eventually leading to its failure. Piping and sloughing are regarded to be the most prominent types of seepage failures along the downstream face of the embankment. In history, there are many cases of dam failure reported due to a lack of proper seepage management, including the Teton Dam in Idaho and Tunbridge Dam in Australia [4].

The application of drains and filters in embankment dams becomes handy as they tend to reduce seepage and loss of soil particles, which in turn improves the slope stability [5]. It has to be noted that, in the case where seepage through the embankment is blocked, then it will find a new route or build-up, leading to slope instability. Therefore, to avoid the aforementioned issues the embankment should include a well-designed internal drainage system. However, the effectiveness of the toe drain can be significantly affected by its shape, location, and most importantly the size of the toe drain. Unfortunately, the information regarding the potential effect of a toe drain size on the slope 
stability of an embankment dam under rapid drawdown conditions is still scarce. A rapid drawdown condition occurs when the water elevation that has reached the peak suddenly drops within a relatively short period of time [6]. The phenomenon can lead to reduced hydrostatic pressure and alteration of pore water pressure in the embankment. In this matter, estimation of velocity of flow through the embankment is also important. To achieve that, Darcy derived an equation that calculates the velocity of flow of water through porous media as illustrated in Eq. 1 [7].

$$
V=K i
$$

Where: V stands for Darcy's velocity, K is the hydraulic conductivity of the porous medium, and $i$ is the hydraulic gradient.

The combination of numerical modeling and finite element method is among the prominent approaches in investigating the nature of seepage through the embankments and the slope stability. GeoStudio is a widely used computer program for seepage and slope stability modeling [8].

In this study, the potential effect of a toe drain size on the slope stability of a homogeneous embankment dam under rapid drawdown conditions is investigated using numerical modeling. In the modeling process, three different sizes $(5 \mathrm{~m}, 10 \mathrm{~m}$, and $15 \mathrm{~m})$ of the toe drain are investigated. Also, two transient flow cases; instantaneous (worst scenario) and 5 days (more realistic) drawdown rates are investigated in GeoStudio.

\section{Methods}

\subsection{General description of the numerical simulation}

Finite element method analyses were performed to investigate the influence of the toe drain size and rapid drawdown rates on the slope stability of the embankment. Three different cases as determined by the toe drain size were taken into consideration. The numerical modeling process was achieved using the GeoStudio software (GeoStudio 2018 R2 v9.1.1.16749). Mainly SEEP/W and SLOPE/W sub-units of the GeoStudio were used for the seepage analysis and slope stability analysis respectively.

\subsubsection{Embankment geometry}

The geometry of the embankment was kept constant in all three main investigations while changing the toe drain size. The width of the embankment is approximately $59 \mathrm{~m}$ at the base as well as $7 \mathrm{~m}$ at the top, while the height of the embankment is $13 \mathrm{~m}$ as shown in Figure 1 . The toe drain located at the downstream toe of the embankment varied from $5 \mathrm{~m}, 10 \mathrm{~m}$ to $15 \mathrm{~m}$. The maximum water level in the reservoir is $10 \mathrm{~m}$. Table 1 provides a summary of the embankment geometry parameters.

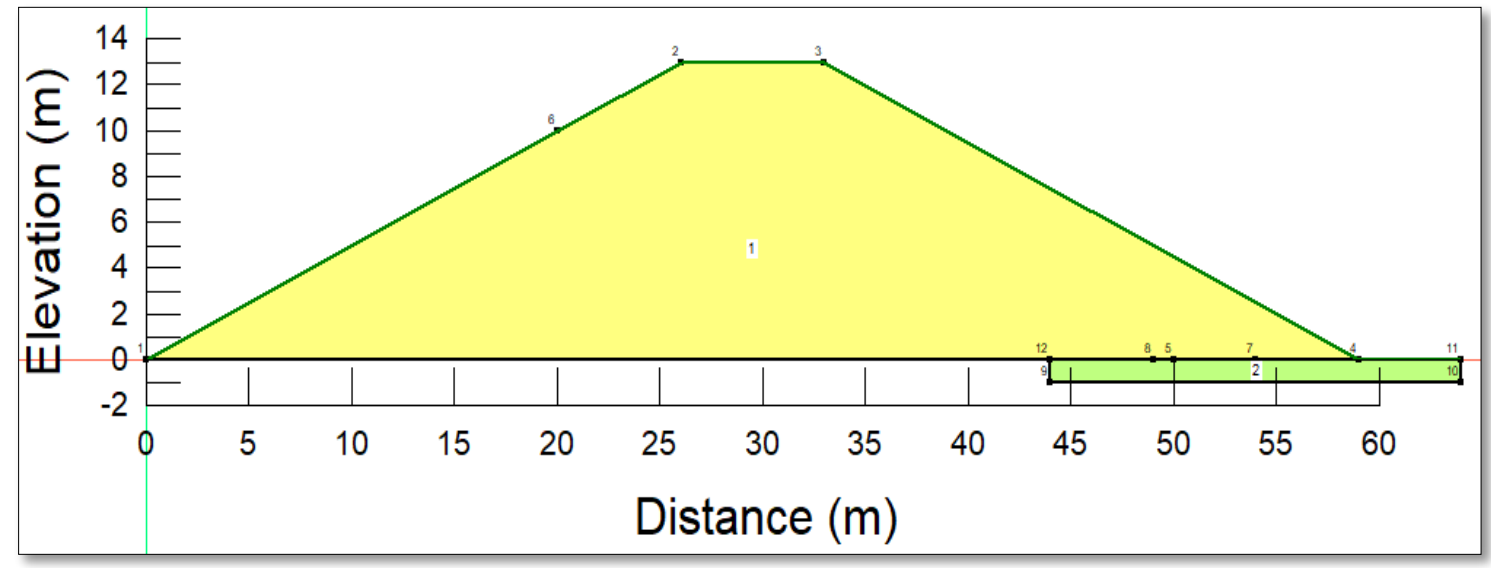

Figure 1 - General embankment geometry

Table 1 - Summary of the embankment geometry parameters

\begin{tabular}{ccc}
\hline Parameter & Unit & Value \\
\hline Bottom width & $\mathrm{m}$ & 59 \\
\hline
\end{tabular}




\begin{tabular}{lcc}
\hline Top width & $\mathrm{m}$ & 7 \\
Embankment height & $\mathrm{m}$ & 13 \\
Maximum water level & $\mathrm{m}$ & 10 \\
Slope, H:V & - & $2: 1$ \\
Toe drain & $\mathrm{m}$ & $5,10,15$ \\
\hline
\end{tabular}

\subsection{Seepage and slope stability analyses}

In general, the SEEP/W water transfer-based analyses were used to assess changing porewater pressure conditions. The instantaneous drawdown case was taken as the worst drawdown scenario and then the rate was increased to 5 days (Figure 2). To simulate the drawdown behavior of the slope in this study, initially, the transient seepage analysis was performed to obtain seepageinduced pore pressures and free groundwater-surface for different drawdown rates.

On the other hand, the slope stability analyses were performed using the SLOPE/W sub-unit of the GeoStudio based on the Spencer method. Generally, the Spencer method allows for unconstrained slip plains which in turn can determine the factor of safety along any slip surface [9].

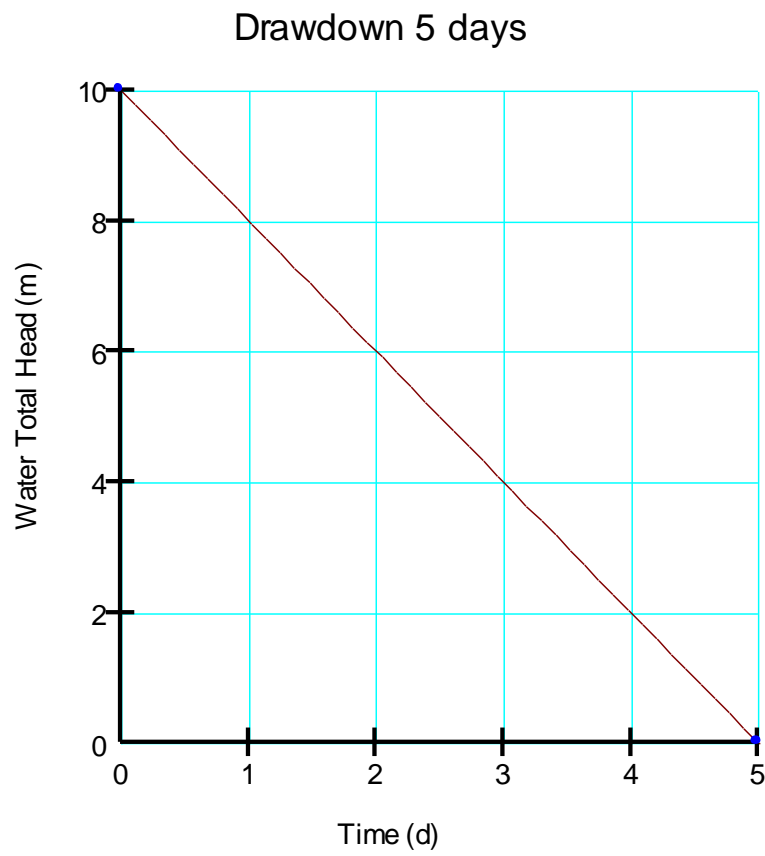

Figure 2 - Water total head function for 5 days drawdown rate

\subsection{Soil material characteristics}

The soil material properties for the embankment were kept constant for all the cases investigated to avoid any variability and capture the effect of the changes in the toe drain sizes. Table 2 provides a summary of the soil material properties used in the seepage and slope stability analyses. The saturated water content, coefficient of compressibility, saturated conductivity, residual water content, soil unit weight, cohesion, internal friction angle, young's modulus as well as Poisson's ratio were the main soil parameters to the model.

Table 2 - Soil properties

\begin{tabular}{lccc}
\hline Soil material properties & Symbol & Unit & Value \\
\hline Saturated water content & $\theta_{s}$ & $\%$ & 43 \\
Coefficient of volume compressibility & $M_{v}$ & $\mathrm{~m}^{2} / \mathrm{kN}$ & $2 \times 10^{-4}$ \\
Saturated conductivity & $K_{\text {sat }}$ & $\mathrm{m} / \mathrm{s}$ & $1 \times 10^{-6}$ \\
Residual water content & $\theta_{r}$ & $\%$ & 5.5 \\
Soil unit weight & $\gamma$ & $\mathrm{kN} / \mathrm{m}^{3}$ & 20 \\
\hline
\end{tabular}




\begin{tabular}{llll}
\hline Cohesion & $c^{\prime}$ & $\mathrm{kN} / \mathrm{m}^{2}$ & 5 \\
Internal friction angle & $\emptyset^{\prime}$ & degrees & 25 \\
\hline
\end{tabular}

\section{Results and Discussion}

The seepage and slope stability analyses were successfully executed using the combination of the finite element method and numerical modeling. From the seepage analysis, the water pressure at the downstream toe of the embankment was observed to increase with the increase in the toe-drain size. From Figure 3, it can be observed that the $15 \mathrm{~m}$ length drain size has higher pore-pressures than the $10 \mathrm{~m}$ and $5 \mathrm{~m}$. In general, in the literature drains have been observed to be important features in the stability of embankments [10-12].

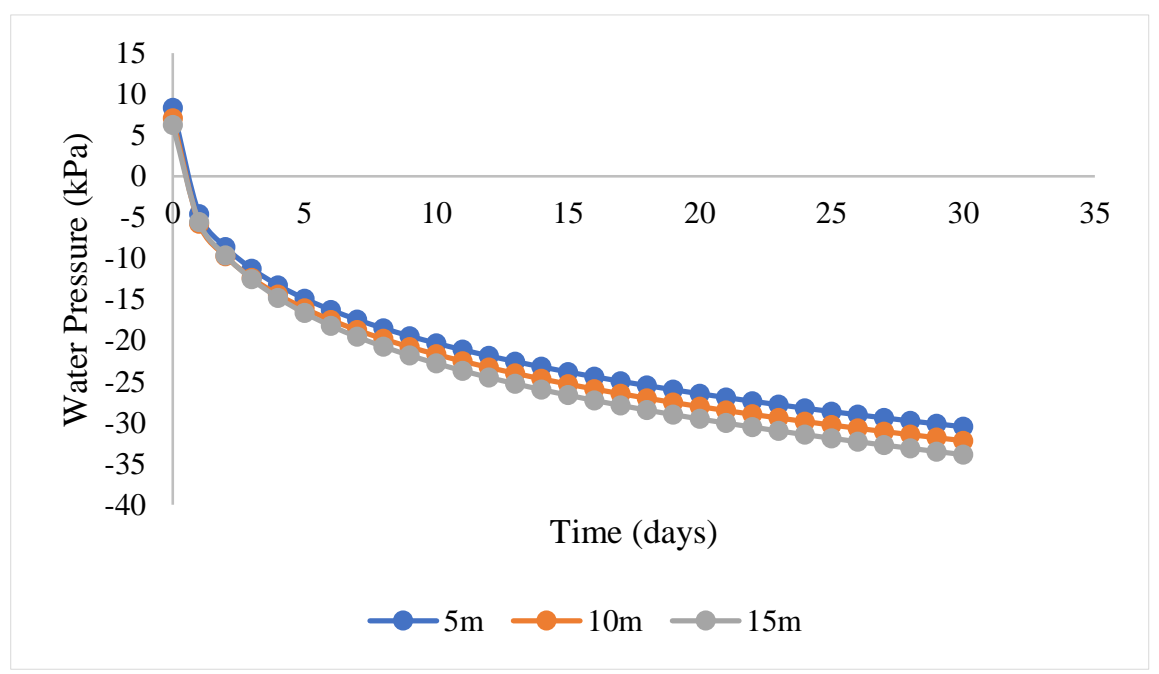

Figure 3 - Pore-water pressure at the upstream face

Contrary to the downstream toe, the pore water pressures at the upstream face of the embankment were observed to be decreasing with the increase in the toe-drain size. From Figure 4, it can be observed that the pore-water pressures from the $15 \mathrm{~m}$ length drain size were slightly higher than those from the $10 \mathrm{~m}$ and $5 \mathrm{~m}$. The phenomenon suggests that, as the size of the toe drain increases, the seepage is more conveniently carried through the embankment allowing easy dissipation of porewater pressures in the embankment after the drawdown.

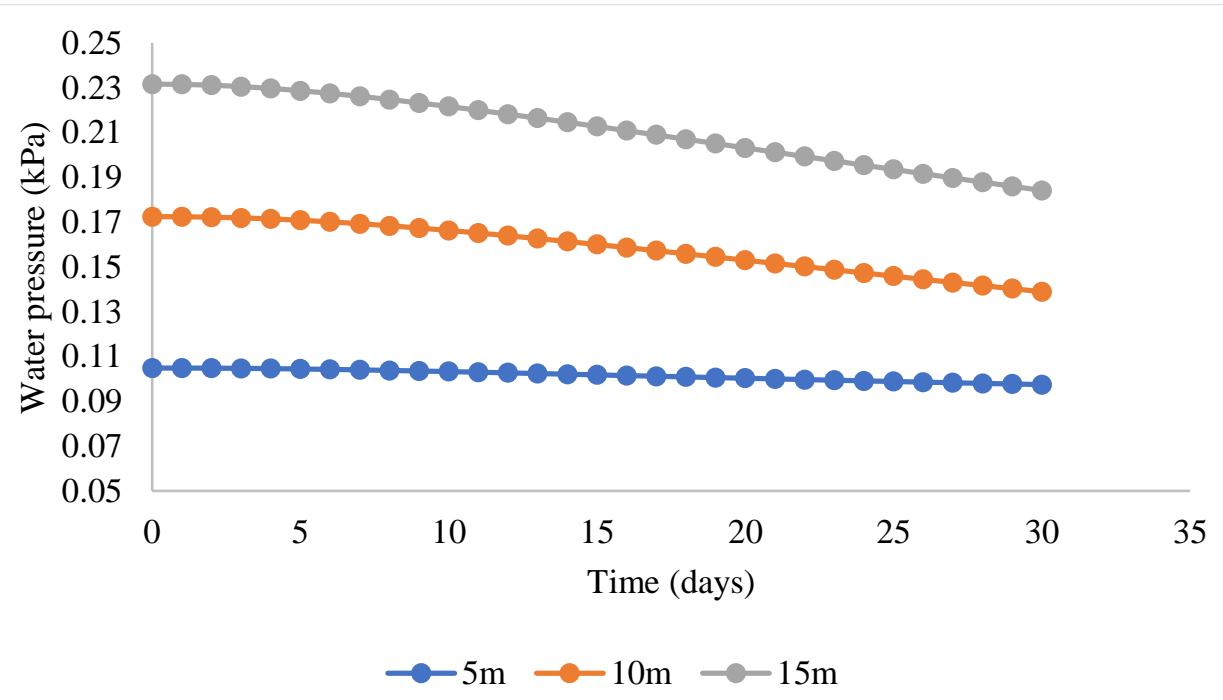

Figure 4 - Pore-water pressure at the downstream toe 
Similarly, from the slope stability analysis, it was observed that the change in the toe drain size affected the factor of safety. From Figure 5 it can be observed that the $15 \mathrm{~m}$ length toe drain size showed to have a bit higher factor of safety in comparison to the $10 \mathrm{~m}$ and $5 \mathrm{~m}$ toe drain sizes. The $5 \mathrm{~m}$ drain size had a minimum size of 0.961 , the $10 \mathrm{~m}$ drain size had a minimum factor of safety of 0.970 , while the $15 \mathrm{~m}$ drain size had a minimum factor of safety of 0.978 .

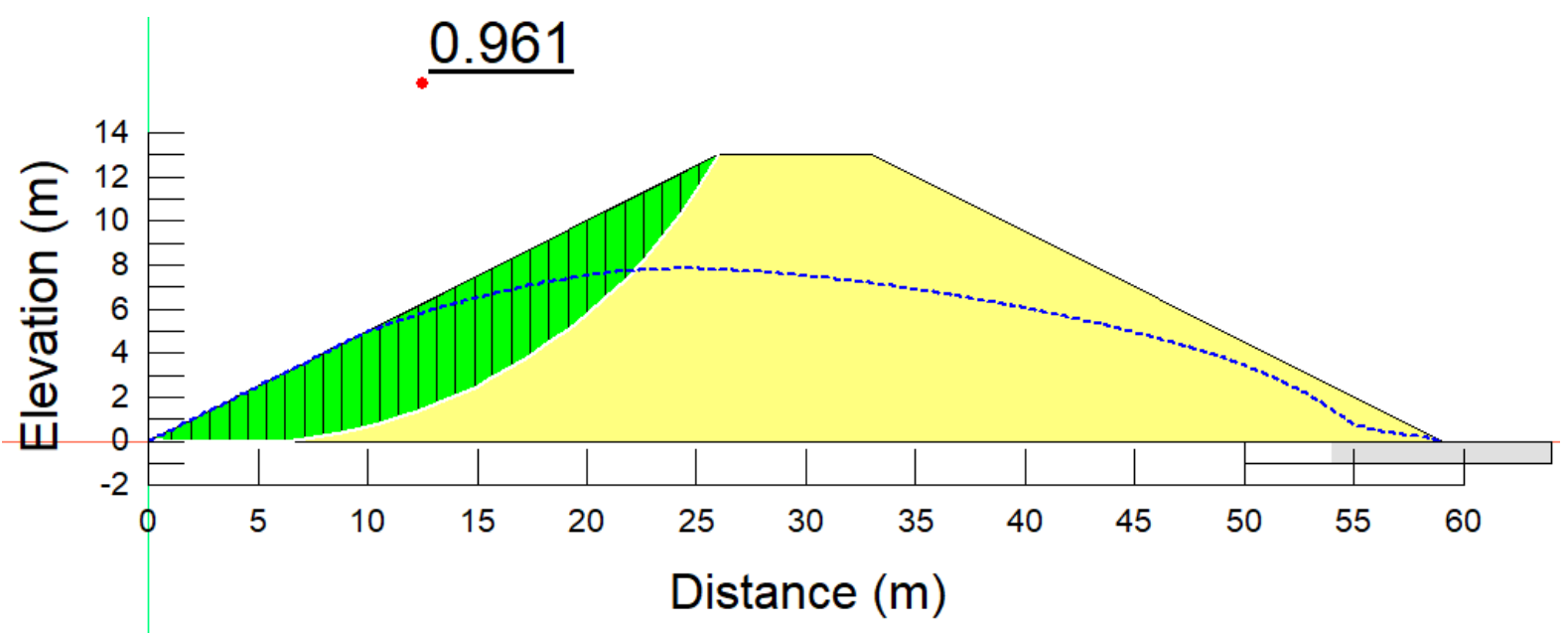

a) $5 \mathrm{~m}$ drain size

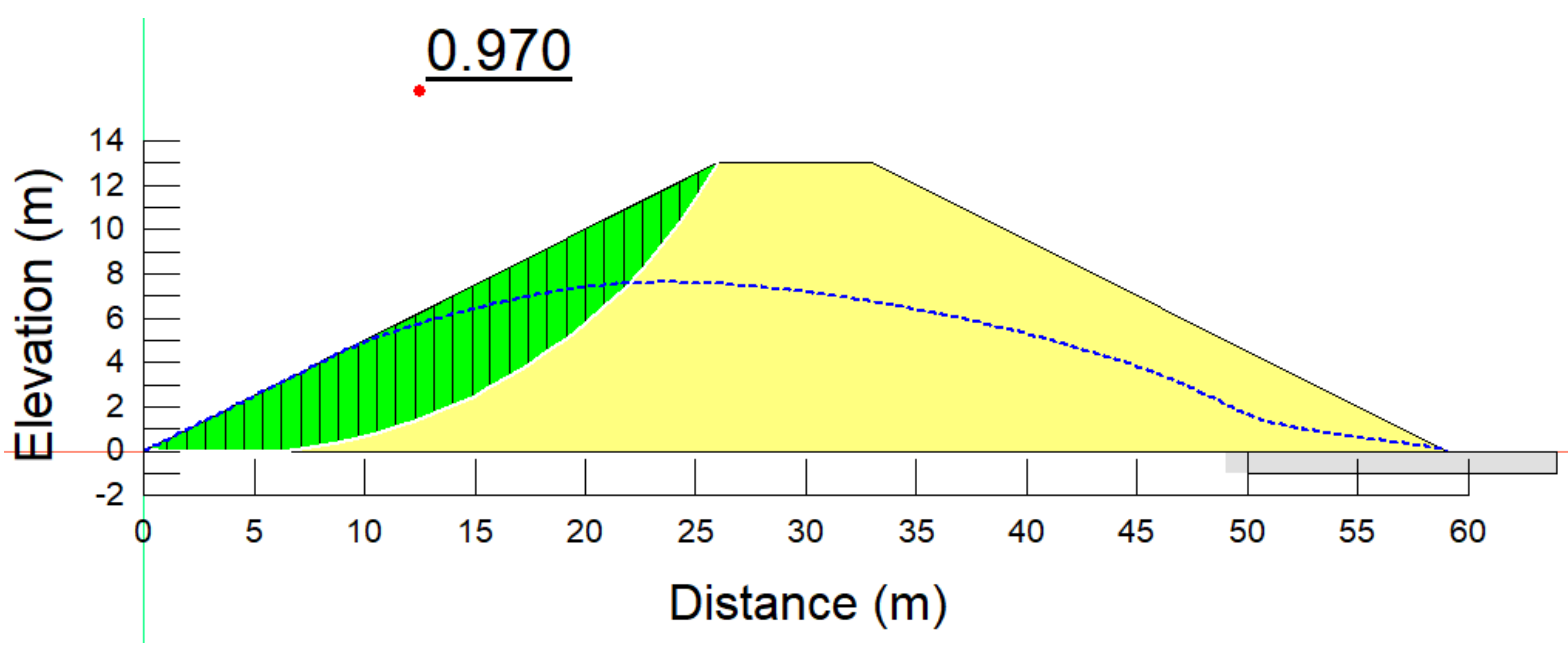

b) $10 \mathrm{~m}$ drain size

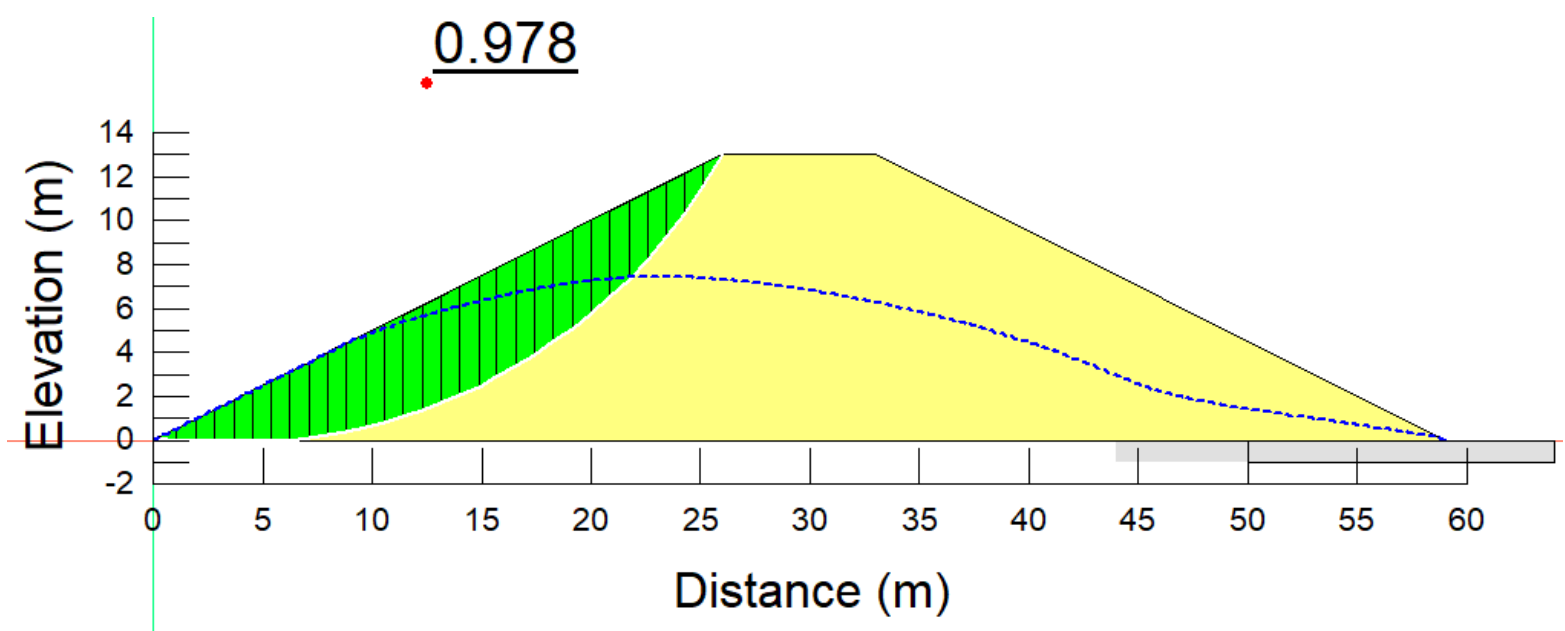

c) $15 \mathrm{~m}$ drain size

Figure 5 - The factor of safety with slip surfaces from 5 days drawdown rate 
From Figure 6, it can be observed that the lowest factor of safety values were obtained somewhere close to the last day of the drawdown. The factor of safety values dropped rapidly during the drawdown period with a gradual increase after the drawdown.

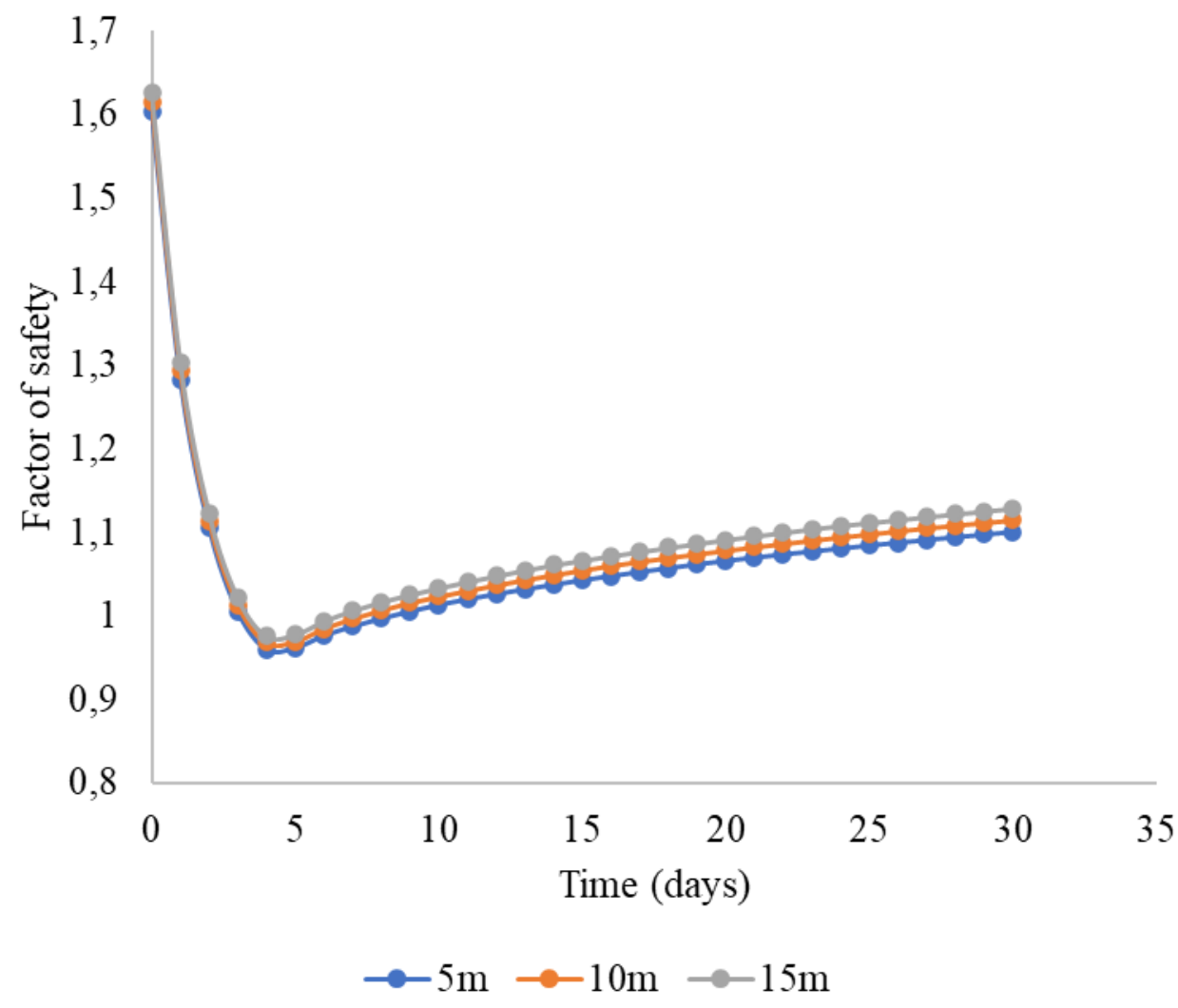

Figure 6 - The trend of the factor of safety values with time

Table 3 provides a summary of the maximum and minimum values of the factor of safety from the instantaneous and 5 days drawdown rates. From both drawdown cases, it can be observed that the factor of safety values was increasing with the increase in the toe drain size.

Table 3 - A maximum and a minimum factor of safety values from the instantaneous and 5 days drawdown rates.

\begin{tabular}{lcrr}
\hline Drawdown rate & Toe drain size & \multicolumn{2}{c}{ Factor of safety } \\
\cline { 3 - 4 } & & Maximum & Minimum \\
\cline { 3 - 4 } Instantaneous & $5 \mathrm{~m}$ & 1.603 & 0.799 \\
& $10 \mathrm{~m}$ & 1.614 & 0.805 \\
& $15 \mathrm{~m}$ & 1.626 & 0.811 \\
\hline 5 days & $5 \mathrm{~m}$ & 1.603 & 0.959 \\
& $10 \mathrm{~m}$ & 1.614 & 0.968 \\
& $15 \mathrm{~m}$ & 1.626 & 0.976 \\
\hline
\end{tabular}

\section{Conclusions}

The potential influence of a toe drain size on the slope stability of an embankment dam under rapid drawdown conditions has been investigated. From the results, it was observed that the porewater pressures at the upstream face of the embankment were decreasing with the increase in the toe drain size, while the pore-water pressures at the downstream toe were increasing with the increase in 
the toe drain size. The factor of safety values was also observed to be affected by the changes in the toe drain size. Therefore, the results from this study revealed further that, there is a significant potential relationship between toe drain size and factor of safety when an embankment is subjected to a rapid drawdown condition.

\section{References}

1. The brumadinho dam rupture disaster, Brazil 2019: Analysis of the narratives about a disaster from the perspective of disaster law / D.W. de Carvalho // Revista de Estudos Constitucionais, Hermeneutica e Teoria do Direito. 2020. DOI: $10.4013 /$ rechtd.2020.122.04.

2. Control of Seepage through Earth Dams Based on Pervious Foundation Using Toe Drainage Systems / M.M. Aboelela // Journal of Water Resource and Protection. - 2016. - Vol. 08, № 12. - C. 1158-1174. DOI: 10.4236/jwarp.2016.812090.

3. A numerical modeling study on the seepage under embankment dams / G. Kheiri, H. Javdanian, G. Shams // Modeling Earth Systems and Environment. — 2020. DOI: 10.1007/s40808-020-00742-9.

4. The failure of Teton Dam / H. Bolton Seed, J.M. Duncan // Engineering Geology. — 1987. DOI: 10.1016/00137952(87)90060-3.

5. Upstream Cutoff and Downstream Filters to Control of Seepage in Dams / F. Salmasi, M. Nouri, J. Abraham // Water Resources Management. — 2020. DOI: 10.1007/s11269-020-02674-6.

6. Reliability analysis of slope stability in earthen dams following rapid drawdown / Z. Kahot, R. Dkiouak, A. Khamlichi // International Review of Applied Sciences and Engineering. - 2019. DOI: 10.1556/1848.2018.0011.

7. Investigation of permeability effect on slip velocity and temperature jump boundary conditions for FMWNT/Water nanofluid flow and heat transfer inside a microchannel filled by a porous media / M. Nojoomizadeh, A. D’Orazio, A. Karimipour, M. Afrand, M. Goodarzi // Physica E: Low-dimensional Systems and Nanostructures. - 2018. Vol. 97. - C. 226-238. DOI: 10.1016/j.physe.2017.11.008.

8. Effect of groundwater table on slope stability and design of retaining wall / R. Ahmad, A.B. Mardhanie, P. Suroso, T.E. Sutarto, R. Alfajri // Journal of Physics: Conference Series. - 2020. - Vol. 1500. - C. 012072. DOI: 10.1088/1742-6596/1500/1/012072.

9. PERFORMANCE OF ANALYSIS METHODS OF SLOPE STABILITY FOR DIFFERENT GEOTECHNICAL CLASSES SOIL ON EARTH DAMS / T.D.S. Pereira, A.D. Robaina, M.X. Peiter, F.D.V.A. Braga, R.B. Rosso // Engenharia Agrícola. — 2016. — Vol. 36, № 6. — C. 1027-1036. DOI: 10.1590/1809-4430-eng.agric.v36n6p1027$1036 / 2016$.

10. Instability of a geogrid reinforced soil wall on thick soft Shanghai clay with prefabricated vertical drains: A case study / J.-F. Xue, J.-F. Chen, J.-X. Liu, Z.-M. Shi // Geotextiles and Geomembranes. — 2014. — Vol. 42, № 4. C. 302-311. DOI: 10.1016/j.geotexmem.2014.05.003.

11. Performance of a geogrid reinforced soil wall on PVD drained multilayer soft soils / J.-F. Chen, A. Tolooiyan, J.-F. Xue, Z.-M. Shi // Geotextiles and Geomembranes. - 2016. - Vol. 44, № 3. - C. 219-229. DOI: 10.1016/j.geotexmem.2015.10.001

12. Measurement and Simulation on Consolidation Behaviour of Soft Foundation Improved with Prefabricated Vertical Drains / C. Qi, R. Li, F. Gan, W. Zhang, H. Han // International Journal of Geosynthetics and Ground Engineering. — 2020. — Vol. 6, № 2. — C. 23. DOI: 10.1007/s40891-020-00208-Z.

\section{Information about authors:}

Timoth Mkilima - Research Fellow, Ardhi University, Dar es Salaam, Tanzania, tmkilima@gmail.com 